Theme: Oxygen Steelmaking

\title{
STATE OF THE ART GAS CLEANING AND UTILIZATION FOR BOF GASES: OPERATIONAL RESULTS AND BENEFITS*
}

\author{
Thomas Germershausen ${ }^{1}$ \\ Christian Fröhling ${ }^{2}$ \\ Matthias Meyn ${ }^{3}$ \\ Volker Trappmann ${ }^{4}$ \\ Jörg Thomasberger ${ }^{5}$
}

\begin{abstract}
Worldwide BOF-based steel plants are faced with demanding environmental requests and rising energy costs. For cleaning of primary gases from the BOF the scrubbing technology is worldwide adapted. For wet-scrubbers there is a direct relation between pressure loss and achievable clean gas dust content. Subsequently main energy consumers within Gas Cleaning Plants are the driving fans. To evaluate actual performance and to identify optimization measures extensive field measurements at existing Gas Cleaning Plants were performed. The operational results from various BOF plants worldwide will be presented and benchmarked. As a conclusion, advanced control strategies for reduced energy consumption and lower environmental impact were developed and implemented.

Keywords: BOF-based steel plants; Reduced energy consumption; Lower environmental impact.
\end{abstract}

1 Engineer, Dr., Executive Vice President Metallurgical Plants, SMS Siemag, Düsseldorf, Germany.

2 Engineer, Dr., General Manager Gas Cleaning, Mechanical/ Energy \& Environmental Technologies, SMS Siemag AG, Düsseldorf, Germany.

3 Engineer, Deputy General Manager Project Planning Gas Cleaning Systems, SMS Siemag AG, Düsseldorf, Germany.

4 Engineer, Project Manager, Order Handling Gas Cleaning Systems, SMS Siemag AG, Düsseldorf, Germany.

5 Engineer, Deputy General Manager Research \& Development and Innovations - Steel Plants \& Caster, SMS Siemag AG, Düsseldorf, Germany.

* Technical contribution to the $45^{\text {th }}$ Steelmaking Seminar, May $25^{\text {th }}-28^{\text {th }}, 2014$, Porto Alegre, RS, Brazil. 


\section{INTRODUCTION}

For cleaning of primary gases from BOF-process, the well approved wet scrubbing technology is worldwide the most applied technology. Most of these installations are running for more than 20-30 years. They were originally designed for compliance with environmental regulations much less stringent and complex than nowadays. The revamp, upgrade and retrofit of these systems to fulfil actual requirements with lowest investment and shortest shut down times is one of the main demands.

For this purpose, a multi-access strategy has been developed and stepwise implemented. This strategy comprises of:

- field measurements to improve understanding of operational behavior;

- technical-tests with a 1:1 scale test-rig supported by comprehensive CFD-simulations;

- development of wet-ESP technology as a retrofit option;

- advanced/improved control technologies to reduce energy consumption.

Main results of the works will be described. It has to be accentuated, that any solution has to be developed and implemented under close consideration of various site specific factors, such as:

- available space;

- actual operational practice;

- type and make of scrubber;

- requested target figures.

\section{MEASUREMENT COMPAIGNS AT VARIOUS BOF PLANTS}

From 2010 to 2012 comprehensive field measurement campaigns at various steel plants worldwide have been executed. For these measurements both plants with older configuration and plants with most recent technology were sampled.

During these campaigns extractive dust measurements at selected locations throughout the gas cleaning plant were performed. In general, dust content in LDGas at the following locations was measured:

- exit of scrubber;

- exit of ID-Fan;

- flare stack;

- exit of Gas holder.

The measurements were done in compliance with VDI Guideline 2066 (isokinetic measurement) with special sample head.

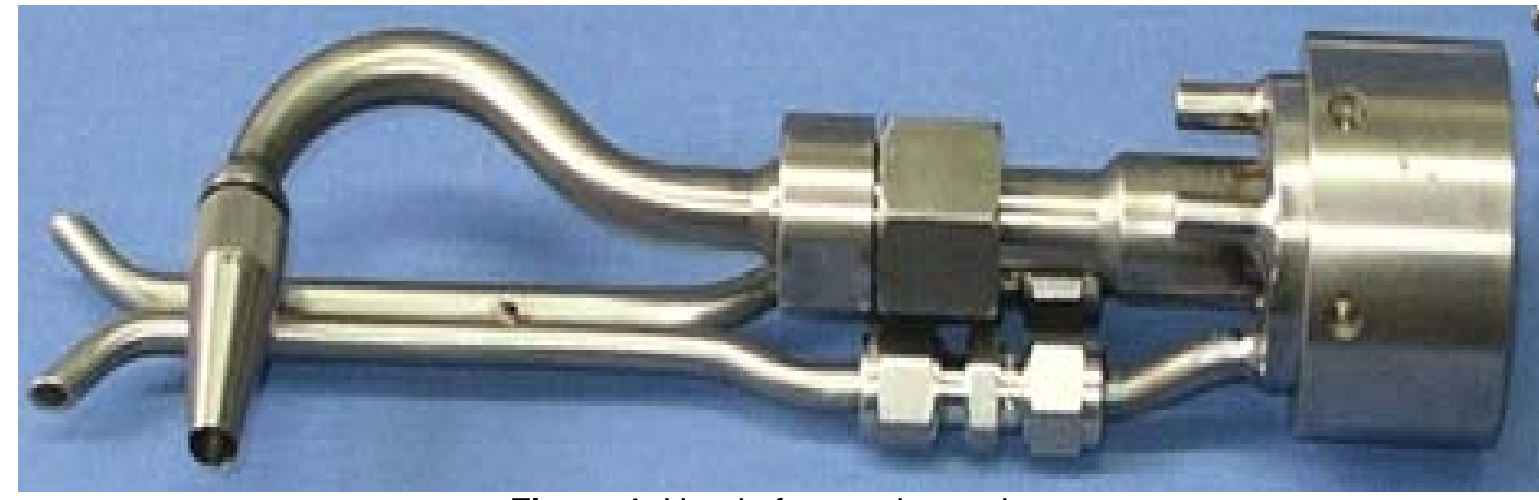

Figure 1. Head of extraction probe.

* Technical contribution to the $45^{\text {th }}$ Steelmaking Seminar, May $25^{\text {th }}-28^{\text {th }}, 2014$, Porto Alegre, RS, Brazil. 


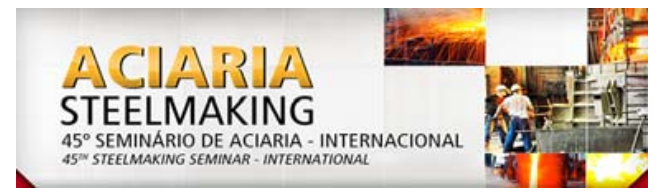

It has to be noted, that due to space limitations within the plant a full compliance regarding the measurement location was not always guaranteed. Nevertheless this imperfection was partly compensated by a careful evaluation of the actual flow pattern in the cross section.

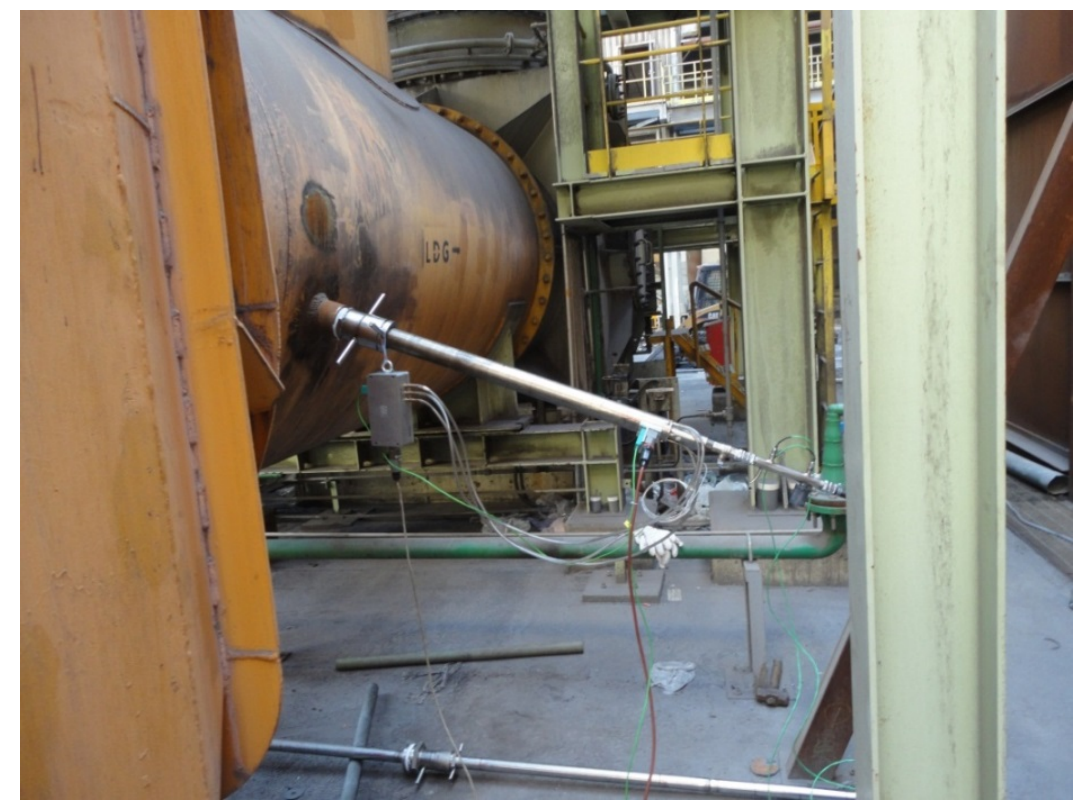

Figure 2. Typical setup for a measurement location at outlet of ID Fan.

To support the dust measurement, in addition:

- all relevant operational data of the Gas cleaning plant (flow rates, temperatures, gas composition, etc.),

- simultaneous samples of scrubbing water (inlet, quencher, outlet) (three samples during blowing time)

- chemical analysis of dust collected on filter blanks

- chemical analysis of dust particles in water samples

- particle size distribution of particles collected on filter blanks

- particle size distribution of particles collected in water samples

- temperature development of scrubbing water

- $\mathrm{pH}$-value of scrubbing water

were collected. These data were analyzed and helped to improve the understanding of the complex thermodynamic and chemical processes throughout the scrubbing unit. The results helped to a great extend to understand typical operational problems and were also used to improve the CFD simulations.

As a main result it can be stated, that with Venturi Scrubbers in advanced design dust contents of far below $30 \mathrm{mg} / \mathrm{Nm}^{3}$ at pressure drops of below $20.000 \mathrm{~Pa}$ can be received on a reproducible basis. This is a significant improvement against previous design and allows significant reduction in electrical energy.

\section{HYDRO-HYBRID SYSTEM}

To achieve lower dust contents without major changes in the available plant configuration, the installation of a supporting wet-ESP may be an interesting option. With this additional cleaning device the pressure drop across venturi scrubber may be reduced and at the same time a lower clean gas dust content of less than 30 $\mathrm{mg} / \mathrm{Nm}^{3}$ may be obtained.

* Technical contribution to the $45^{\text {th }}$ Steelmaking Seminar, May $25^{\text {th }}-28^{\text {th }}, 2014$, Porto Alegre, RS, Brazil. 

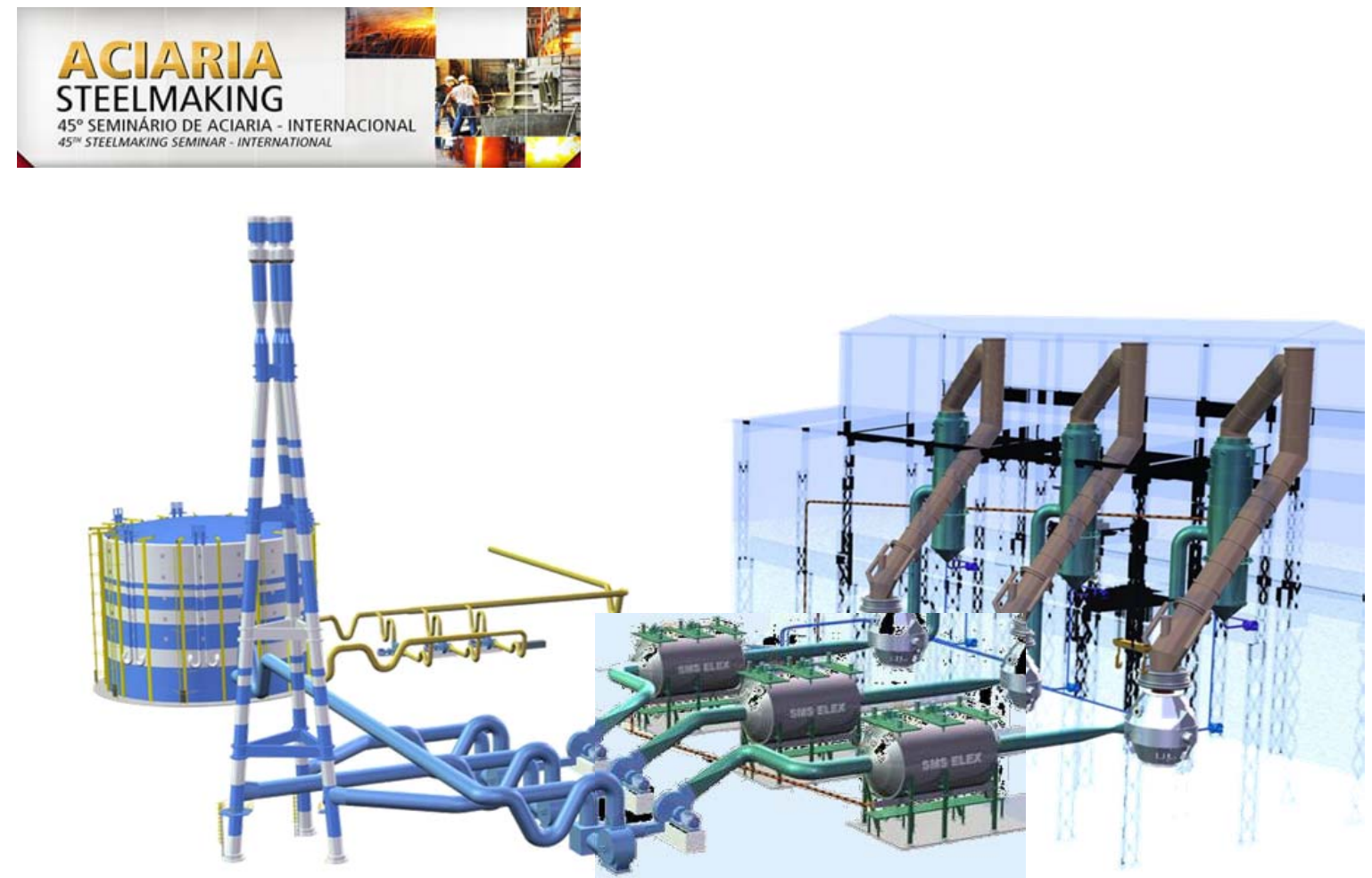

Figure 3. General arrangement of Hydro-hybrid system.

The wet-ESP may be installed between scrubber and ID fan or at the outlet of ID fan prior to the flare stack. It has to be noted, that the first configuration is preferred.

\section{OPERATIONAL RESULTS OF MODERN GAS RECOVERY PLANT}

Regaining of process gases with high, useable energy content like carbon monoxide is an important issue in steel production nowadays. Apart from sustainable reasons, it can also lead to cost reduction.

For a german steel plant, an existing configuration was retrofitted with a Gas recovery System. Amongst other issues, the very limited space for the installation of the switch-over-station was the main task to be resolved.

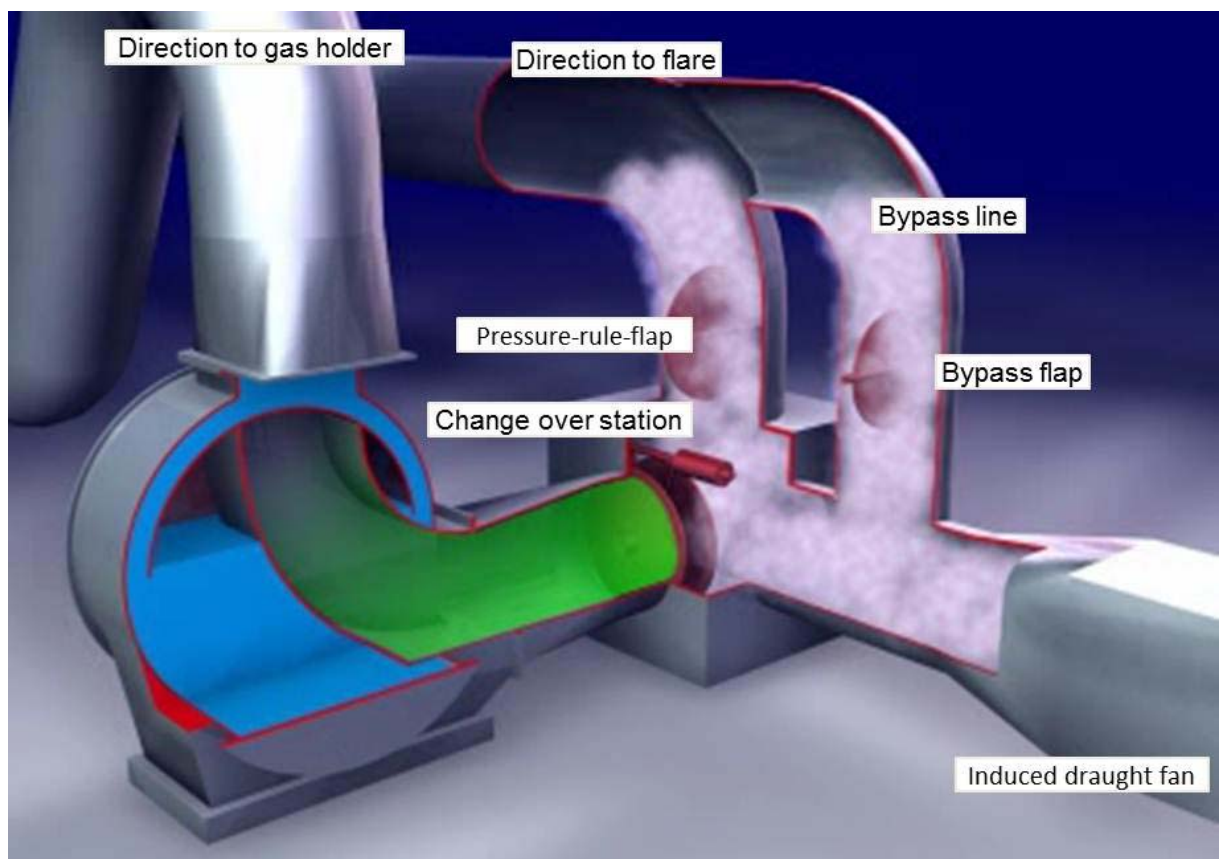

Figure 4. Main components of Change over station.

* Technical contribution to the $45^{\text {th }}$ Steelmaking Seminar, May $25^{\text {th }}-28^{\text {th }}, 2014$, Porto Alegre, RS, Brazil. 


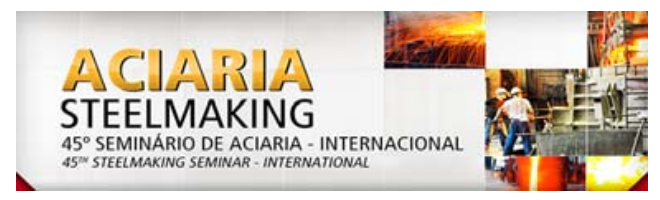

The system is optimized with time of the blowing process, which previously took around 18 minutes. Meanwhile it is possible to recover converter gas up to 16 minutes.

To guarantee clean gas with high fuel value an adjusting ring was refitted. Because of mobile changeover applications the adjusting ring reduces undesired mixture of gas and air.

The details of the patented gas cleaning control at the skirt will be explained in the next chapter. In brief it regulates driving speed of ID-Fan in relation to converter hood pressure. A reliable cleaning range at lower energy costs is ensured.

After passing ID-Fan the converter gas flows towards the new developed switch over station. The operations are regulated by an installed mess concept analyzing the composition of the gas. Based on values for carbon monoxide, oxygen and carbon dioxide the flare operation or gas recovery is started. Changes between them are arranged by clapping the different flaps and lines.

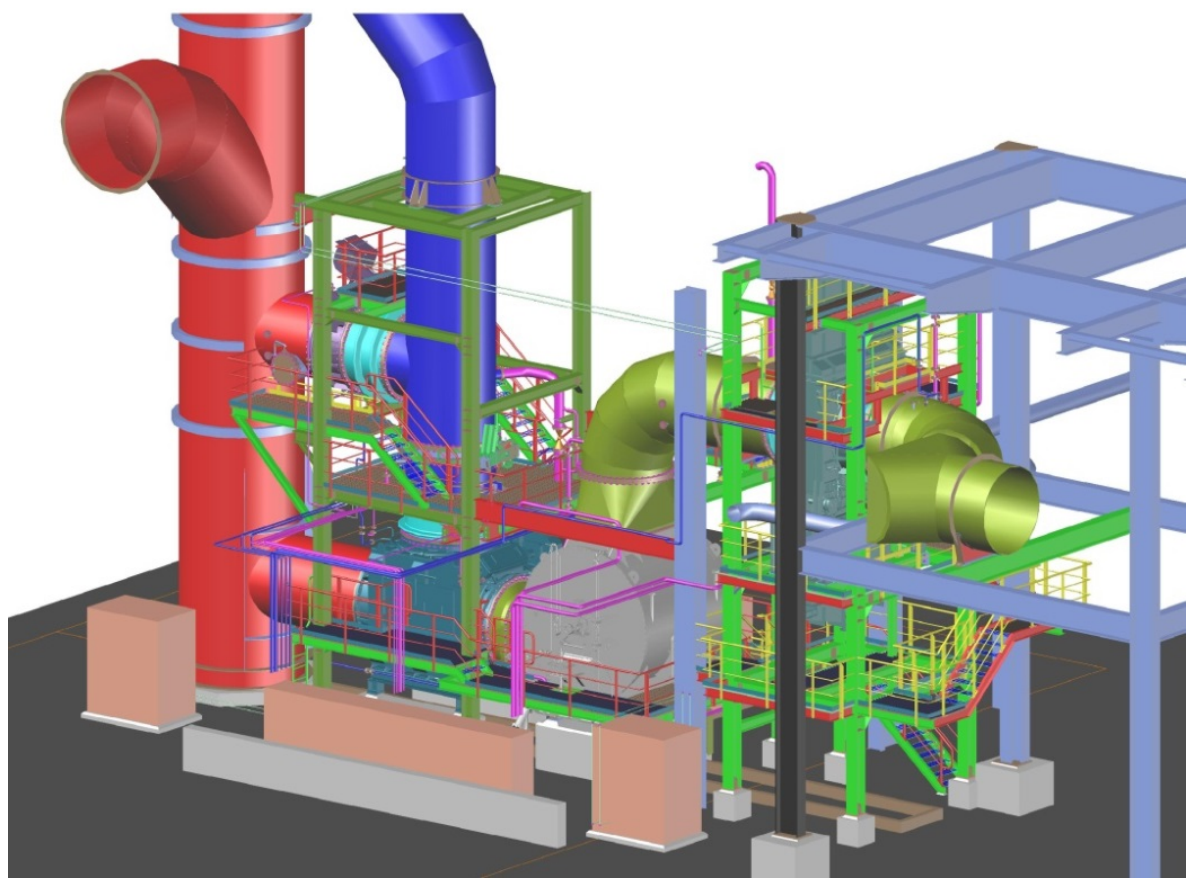

Figure 5. 3D-view of Change over station in compact design.

The certified Insitu mess system is double secured in case of incidents. In emergencies a switch from gas recovery to flare condition follows. Analysis systems are installed to close the gas holder as last possibility to prevent an explosion between $\mathrm{CO}$ and rising $\mathrm{O} 2$.

The converter gas which is saved in the gas holder is guided to the modernized walking-beam furnaces. Through the new installed combination burners up to 80 percent of natural gas could be substituted by recovered converter gas to heat slabs up. This leads to energy savings and a substantial reduction of extruding emissions.

Calculated with a amortization period of two years the operator saves approx.. $40,000 \mathrm{kWh}$ and reduces the impact on the environment by $100 \mathrm{~m}$ tons of $\mathrm{CO}_{2}$ per year. This example displays solutions which save costs and resources significantly.

* Technical contribution to the $45^{\text {th }}$ Steelmaking Seminar, May $25^{\text {th }}-28^{\text {th }}, 2014$, Porto Alegre, RS, Brazil. 


\section{ADVANCED CONTROL STRATEGY FOR GAS CLEANING}

\subsection{Initial Situation}

Focusing on the gas cleaning process at converters (Baumco System), ascended primary gas is cooled through a cooling-water duct, then water pollinized by a vent gas scrubber and finally managed to a stack or a gas recovery system for extraction and purification.

Different operating conditions of the converter lead to different pressure relations in the off gas duct. To guarantee a sufficient throughput at all stages, ID-Fan - placed downstream the scrubber process - usually operates at maximum driving speed. This results in high energy consumption and costs. The Venturi throat at the vent gas scrubber meanwhile regulates the targeted under-pressure.

\subsection{Innovation}

SMS Siemag developed a dynamic control of the ID-Fan. The GasCleaningControl, applied for patent, adjusts high frequent changes in the converter hood pressure by the Venturi throat whereas ID-Fan takes over at low frequent changes.

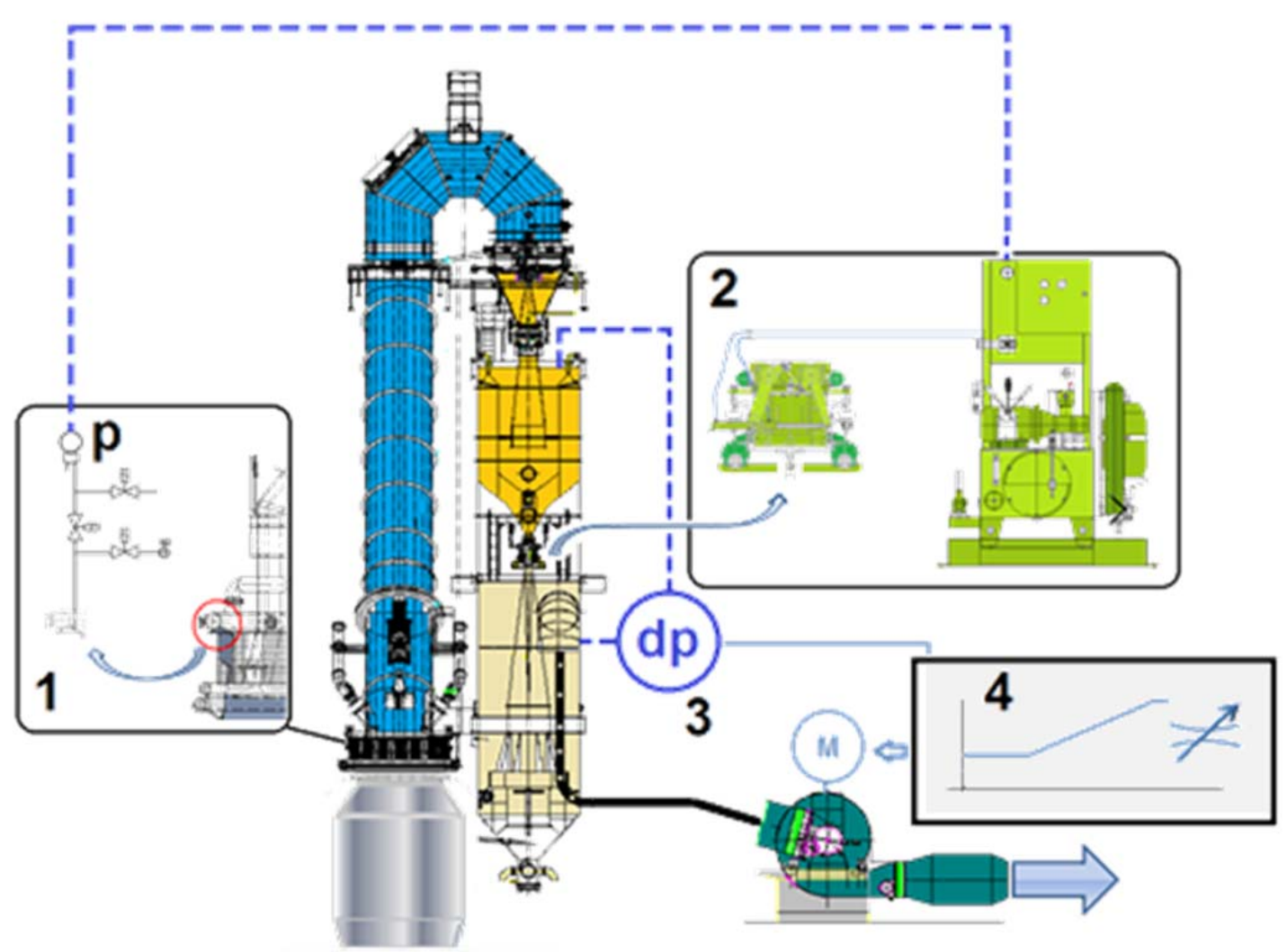

Figure 6. Control scheme pressure control at the converter.

\subsection{Procedure}

When the converter gas passes the skirt, pressure measurement with cleaning valves (1) takes place. This result leads to a regulation of the Venturi throat (2), which has an optimal working range of opening level between $15 \%$ and $60 \%$. The

* Technical contribution to the $45^{\text {th }}$ Steelmaking Seminar, May $25^{\text {th }}-28^{\text {th }}, 2014$, Porto Alegre, RS, Brazil. 


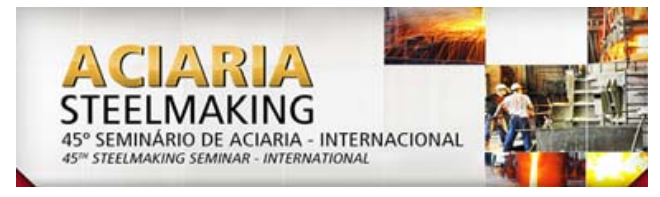

switching procedure works with a hydraulic unit as an actuator. When differential pressure (> 120 mbar, ideally 150 mbar) across the Venturi throat during the oxygen blowing is detected (3), rotational speed gets regulated (4). If the set point for Venturi throat or differential pressure is out of range, the set point for rotational speed of fan will be adjusted accordingly.

\subsection{Benefits}

The disadvantage of the state of the art setup with constantly high driving speed at frequent hood pressures is disposed. While the GasCleaningControl ranges the changes of the converter pressure by parallel adjusting of drive speed, electricity costs are saved.

A further advantage of the trackable pressure course is reliable measurement of clean gas performance at $20-30 \mathrm{mg} / \mathrm{Nm}^{3}$. So compliance with targeted values is certainly ensured.

\section{IMPROVED CONTROL STRATEGY FOR BAG HOUSE SYSTEMS}

A main goal of secondary dedusting systems is to reach a maximum flow rate at the extraction points with as minimal energy consumption as possible. The Gas Cleaning Assistant by SMS Siemag is an innovation with a new approach to reach the objectives.

\subsection{Conventional Methods of Gas Cleaning Plants}

Gas cleaning systems are regulated basing on a matrix. This includes set point values for flap positions at each process phase. If necessary, there is an alignment of the pressure for the whole system.
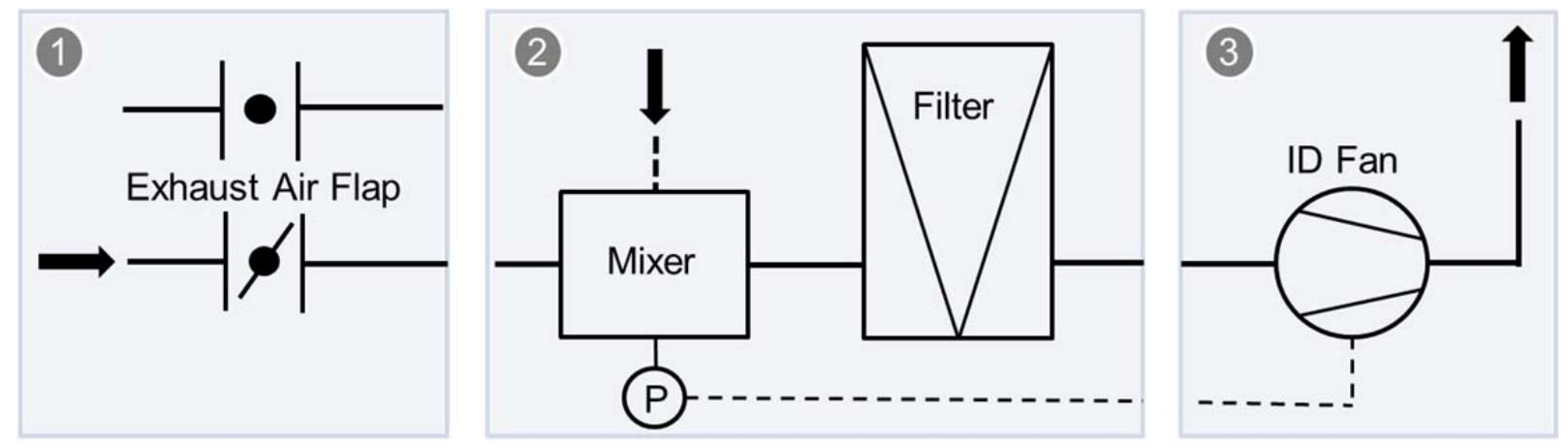

Figure 7. Process steps of gas cleaning procedure.

All flap positions have to be feuded into a matrix manually (1). So every combination leads to a new row. Disadvantage is a nonlinear flap function which prevents calculating in relations.

A constant under pressure in the main pipe is set. It applies for almost all process stages (2). But according to the nonlinear flap function there is consequently to consider a nonlinear network resistance.

The ID-Fan speed is controlled by keeping the previously set pressure constant (3). This leads to a disproportion with the process parameters like air flow. Energy efficiency is suboptimal due to the under pressure in every process step.

* Technical contribution to the $45^{\text {th }}$ Steelmaking Seminar, May $25^{\text {th }}-28^{\text {th }}, 2014$, Porto Alegre, RS, Brazil. 


\subsection{Innovation}

The Gas Cleaning Assistant transforms the pipeline network into a mathematical model with immediate calculation. This results in a calculated required under pressure in main sewer for each process step. Furthermore the required flap position for every flap in the network is determined.

\subsection{Benefits}

In comparison to the traditional approach the optimal flap positions are calculated instead of set manual (1). The network is analyzed with high accuracy because of consideration of network resistances (2). To avoid high under pressure in every process step the Gas Cleaning Assistant arranges variable under pressure (3). This leads to excellent energy efficiency.

\subsection{Set up for Retrofit}

At existing plants the Gas Cleaning Assistant will be delivered as PC system. It communicates with the existing Dedusting-PLC. Dependent on process requirements the mathematical model will be calculated and the flap positions and the optimal under pressure is transferred to the existing system. There are no additional measurements required.

\section{NOVEL GAS ANALYZER FOR HIGH CO-CONTAING GASES}

\subsection{Initial Situation}

An important parameter for process control of the converter is the exhaust gas analysis. The measurement of the $\mathrm{CO}$ concentration in the exhaust gas is used for the determination of the process end. A too long melt refining leads to the burning of alloying elements and the oxidation of iron.

Another application of the gas analyzer at the converter is to control a measurement of $\mathrm{O}_{2}$ and $\mathrm{CO}$, if the exhaust gas is passed into a gas holder or flared off. If the $\mathrm{O}_{2}$ concentration in the exhaust gas is greater than $2 \%$ at a CO concentration of at least $30 \%$ it is not possible to store the gas in the gas holder, due to the risk of explosion.

\subsection{Solution}

The in-situ laser gas analysis system utilizes a transmitter / receiver configuration to measure the average gas concentration of $\mathrm{O}_{2}$ and $\mathrm{CO} / \mathrm{CO}_{2}$ along the optical path. A tuneable-diode-laser emits infrared radiation of variable wavelength and the receiver detects the radiation in transmission. The absorption of gas molecules reduces the detection signal depending on the gas concentration. The tunable range of a diode laser is small in relation to the absorption bands. Therefore, such a laser system can only measure individual absorption bands. For different gases, e.g. $\mathrm{O}_{2}$ and $\mathrm{CO}$ two laser systems must be used. If the absorption bands are close together, such as for $\mathrm{CO}$ and $\mathrm{CO}_{2}$, it is also possible to determine the concentration of both gases with one laser system. For process monitoring at the converter are at least two lasers necessary one for $\mathrm{CO} / \mathrm{CO}_{2}$ and one for $\mathrm{O}_{2}$.

* Technical contribution to the $45^{\text {th }}$ Steelmaking Seminar, May $25^{\text {th }}-28^{\text {th }}, 2014$, Porto Alegre, RS, Brazil. 
In spite of high dust loads in the exhaust gas to achieve a sufficiently high transmission, it is necessary to shorten the measuring path by insertion pipes. Thus, the insertion pipes not clogged with dust, blowing with a purge gas (nitrogen) is necessary.

\subsection{Installation Setup}

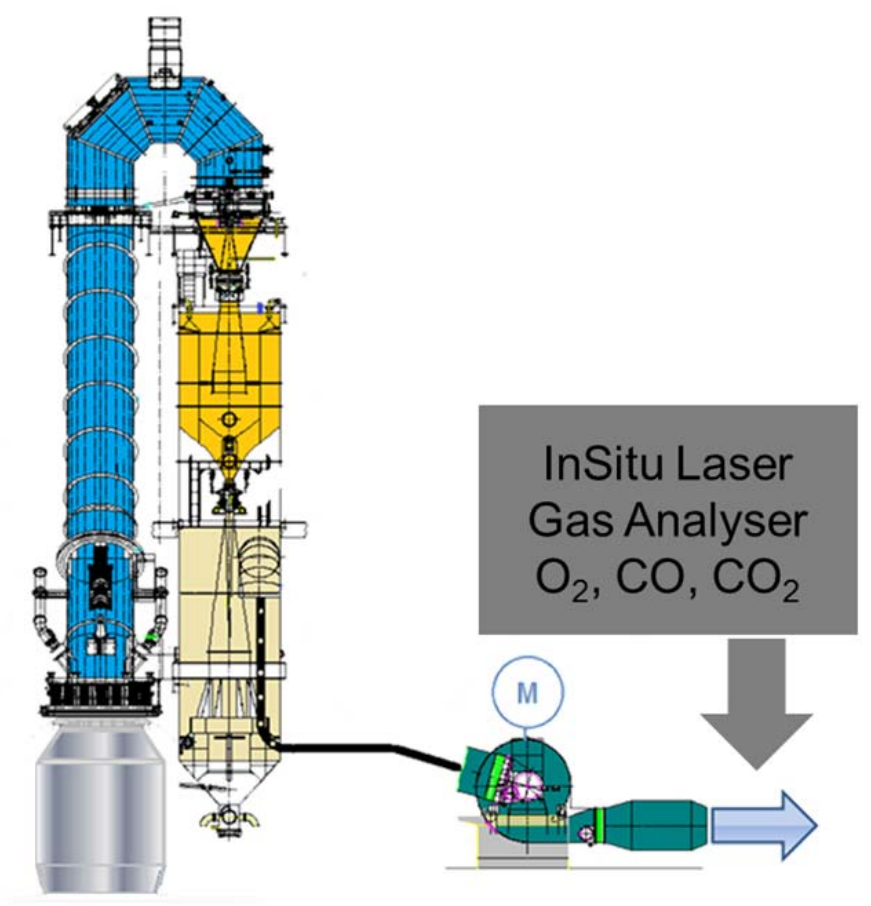

Figure 8. Schematic of measurement position of in-situ laser gas analyzer.

The new in-situ laser gas analyzer is installed after the ID-fan and silencer. A temperature and a pressure transmitter at the measurement position are necessary.

\section{SUMMARY}

The presented solutions represent a number of variations to effectively revamp resp. retrofit existing scrubber-based gas cleaning systems with state-of-the-art technology at minimized costs and shut-down times. What configuration is the most appropriate has to be case-wise decided under consideration of site-specific factors, local laws and regulations and last but not least special needs of operators.

* Technical contribution to the $45^{\text {th }}$ Steelmaking Seminar, May $25^{\text {th }}-28^{\text {th }}, 2014$, Porto Alegre, RS, Brazil. 